\title{
Suitability of endogenous reference genes for gene expression studies with human intraocular endothelial cells
}

\author{
Ruoxin Wei, Elizabeth Anne Stewart and Winfried M Amoaku*
}

\begin{abstract}
Background: The use of quantitative real-time reverse transcription polymerase chain reaction (qRT-PCR) has become widely applied as a method to measure transcript abundance. In order to be reflective of biological processes during health and disease this method is dependent on normalisation of data against stable endogenous controls. However, these genes can vary in their stability in different cell types. The importance of reference gene validation for a particular cell type is now well recognised and is an important step in any gene expression study.

Results: Cultured primary human choroidal and retinal endothelial cells were treated with the immunostimulant polyinosinic: polycytidylic acid or untreated. qRT-PCR was used to quantify the expression levels of 10 commonly used endogenous control genes, TBP, HPRT1, GAPDH, GUSB, PPIA, RPLPO, B2M, 185 rRNA, PGK1 and ACTB. Three different mathematical algorithms, GeNorm, NormFinder, and BestKeeper were used to analyse gene stability to give the most representative validation. In choroidal endothelial cells the most stable genes were ranked as HPRT1 and GUSB by GeNorm and NormFinder and HPRT1 and PPIA by BestKeeper. In retinal endothelial cells the most stable genes ranked were TBP and PGK1 by GeNorm and NormFinder and HPRT1 by BestKeeper. The least stable gene for both cell types was 185 with all 3 algorithms.

Conclusions: We have identified the most stable endogenous control genes in intraocular endothelial cells. It is suggested future qRT-PCR studies using these cells would benefit from adopting the genes identified in this study as the most appropriate endogenous control genes.
\end{abstract}

Keywords: Choroid, Retina, Endothelial cells, Housekeeping gene, Endogenous control, Polymerase chain reaction

\section{Background}

Gene expression analysis is important in the identification of new biological and disease mechanisms. Realtime reverse transcription quantitative polymerase chain reaction (qRT-PCR) is one of the most widely applied methods to measure transcript abundance. Whether the results are truly reflective of biological processes is dependent on normalisation of data against stable endogenous controls, often referred to as housekeeping genes. A housekeeping gene is a constitutively expressed gene that is expressed in all cells of an organism [1]. An ideal housekeeping gene should be expressed at the same level in different types of cells [2]. However, whilst

\footnotetext{
* Correspondence: Winfried.amoaku@nottingham.ac.uk

University of Nottingham, Division of Ophthalmology and Visual Sciences, B Floor, Eye and ENT Building, Queen's Medical Centre, Nottingham NG7 2UH,
} UK

some of the reference genes are expressed at relatively constant levels, others may vary depending on the experimental conditions, [3] and sample type and quality [4]. A number of reports indicate that no housekeeping gene can be considered to be suitable for all conditions [2,5-7]. Such variation of reference genes may lead to inaccurate measurement of expression levels of target genes and a significant alteration of results [8]. Thus, choosing an appropriate reference gene is critical in validating the quality of gene expression studies especially using qRT-PCR. A proper validation of endogenous controls has already been extensively applied to various tissues, and become an essential requirement for accurate qRT-PCR analysis [9]. To date, despite the increase in gene expression research on intraocular endothelial cells, there are no reports of validated set of reference genes for human intraocular endothelial cells, including 
human choroidal endothelial microvascular cells (hCEC), and human retinal endothelial microvascular cells (hREC).

Toll-like receptors (TLRs) are known to play a key role in innate immune responses, inflammation [10] and angiogenesis [11]. TLRs are expressed in many cell types, although their localisation within the cells varies, and are activated by several endogenous and exogenous substances [12]. In the eye TLRs are thought to be important in the inflammatory diseases $[13,14]$ diabetic retinopathy [15], and age-related macular degeneration (AMD) [16-18]. Angiogenic factors and proinflammatory cytokines are secreted after the activation of TLR-mediated signalling pathways when stimulated by specific ligands such as double-stranded RNA (TLR3-specific) and lipopolysaccharide (TLR4-specific) $[19,20]$. Polyinosinic:polycytidylic acid (Poly(I:C)), an immunostimulant, is a well characterised TLR3 ligand [21]. Poly(I:C) (TLR3) stimulation of intraocular endothelial cells, therefore, provides a suitable model for investigating housekeeping gene stability in these cells under stimulated conditions.

There are several statistical programmes developed to assess the appropriateness of reference genes. Most of them use different approaches to evaluating reference stability, and have previously been reported to yield different rankings of reference genes. These include GeNorm [4], BestKeeper [22] and NormFinder [23] which are thought to determine the most stable reference genes from a set of tested genes for each tissue sample.

GeNorm, a Visual Basic Application for Microsoft Excel, relies on the principle that the expression ratio of two ideal reference genes is identical in all samples, regardless of the experimental condition or cell type [4]. GeNorm provides a measure of gene expression stability $M$ for each reference gene as the average pairwise variation $V$ between that individual gene and all other tested candidate genes. For every combination of two internal control genes $j$ and $k$, an array $A_{j k}$ which consist of logarithmically transformed expression ratios is calculated (m). The gene-stability measure $M_{j}$ is calculated as the arithmetic mean of all pairwise variations $V_{j k}$ [4]. Genes with the most stable expression have the lowest $M$ value, and the gene with the highest $M$ value has the least stable expression. Stepwise exclusion of the gene with the highest $M$ value allows ranking of the tested genes according to their expression stability, ending with a combination of the two most stable genes left. Pairwise variation $(\mathrm{V})$ is the level of variation in average reference gene stability with the sequential addition of each reference gene to the equation (for calculation of the normalisation factor). This starts with the two most stably expressed genes, followed by the inclusion of a 3rd, 4th, 5th gene etc. A large variation means that the added gene has a significant effect and should preferably be included for calculation of a reliable normalization factor. Most publications use 0.15 as a cut-off value, below which the inclusion of an additional reference gene is not required [24]. Another Excel-based program, BestKeeper, uses repeated pair-wise correlation analysis to determine the optimal reference genes [22]. This program uses cycle threshold $(\mathrm{Ct})$ values of candidate reference genes instead of relative quantities. It employs pair-wise correlation analyses to calculate the Pearson correlation coefficient $(r)$ for each candidate reference gene pair as well as the probability of correlation significance ( $p$-value). Initial estimation of the data calculated variations (standard deviation, SD and coefficient of variance, $\mathrm{CV}$ values) for all the candidate reference genes show the overall stability in gene expression, from the most stable expression (with the lowest variation) to the least stable one (with the highest variation). Any candidate gene with the SD value higher than 1 is considered inconsistent [22]. Furthermore, each sample is analysed as efficiency corrected intrinsic variation of $\mathrm{x}$-fold, over or under expression. Over 3-fold over- or under- expression is considered to be removed [22].

A further Visual Basic Application, NormFinder, assesses all reference candidate genes by a model-based approach based on inter- and intra-group gene expression variations [23]. NormFinder analyses data on a linear scale through any quantitative method using a model-based approach [23]. The candidate genes are assigned a value as a measure of their stability. Lower values are indicative of low intra- and intergroup variations and of greater stability. NormFinder calculates the stability value for all candidate normalization genes tested in the sample set, and selects two best genes with minimal combined inter- and intra- group expression variation [23].

The aim of this study was to determine the most suitable and stable housekeeping genes for use in the study of hCEC and hREC gene expression with RT-qPCR. This was done by assessing the stability of 10 commonly used housekeeping genes using three different mathematical algorithms in both untreated and poly(I:C) stimulated hCEC and hREC.

\section{Results and Discussion}

A number of studies on the validation of reference genes have been done for different species, and tissues. Software-based applications such as GeNorm, NormFinder, BestKeeper were used to perform statistical identification of the best reference gene from a group of candidate genes in a defined set of biological samples. Ten commonly used qPCR reference genes were investigated for the expression stability in hCEC and hREC using three software programs. Although the three programs 
produced similar results, the ranking of investigated genes were not identical due to the different algorithms [25]. As the three programs, GeNorm, NormFinder and BestKeeper, use different approaches to evaluating reference stability; have been previously reported to yield different rankings of reference genes [25]. The M-values obtained from GeNorm, variability measurements from NormFinder, and the coefficients of correlation from BestKeeper were used as weights in the aggregation process.

\section{Expression of the endogenous control genes in hCEC and hREC}

The expression of 10 commonly used reference genes, including TBP, HPRT1, GAPDH, GUSB, PPIA, RPLPO, $B 2 M, 18 S, P G K 1$ and $A C T B$ [26] (Table 1) were measured using unstimulated and stimulated hCEC and hREC using qRT-PCR (Figure 1).

\section{Reference gene validation in hCEC}

Endogenous gene expression in 12 hCEC samples (1 unstimulated hCEC and 3 stimulated with poly(I:C) for $1 \mathrm{~h}, 6 \mathrm{~h}$ or $24 \mathrm{~h}$ for each of 3 individual donor samples) was analysed with each of the 3 mathematical algorithms. The input data for GeNorm and NormFinder was relative quantities transformed by the comparative Ct method, while the data for BestKeeper was raw Ct values.

When GeNorm applet was used, HPRT1 and GUSB were recommended as the most stable gene combination with the lowest $\mathrm{M}$ values and $18 S$ was highest (Figure 2A). Pairwise variation analysis of the endogenous genes indicated, in future studies, the sufficiency of two reference genes for accurate normalisation (Figure 2B), there is no need for inclusion of additional reference genes.

NormFinder produced comparable results to GeNorm, HPRT1 was the most stable slightly more than, PGK1 and GUSB with similar stabilities (Figure 2C). These results confirmed if using a single gene, HPRT1 has the lowest variability. The least stable reference gene was again 18S (Figure 2C). Thus, although the underlying principles and calculations of GeNorm and NormFinder are different, there was a correlation between the results obtained from them.

Outputs from the BestKeeper were slightly different from the previous two analyses, as with GeNorm and NormFinder, BestKeeper ranked HPRT1 as the most stable, but PPIA was ranked as the second most stable reference gene, with GUSB third (Figure 2D) (Additional file 1). These genes showed the lowest SD according to BestKeeper and were thus considered the most stable reference genes. They were also listed among the three most stable genes by NormFinder and GeNorm, whereas $18 S$ was consistently ranked the least stable candidate in hCEC by all three programs. However, all of the candidate reference genes could be considered as endogenous genes, since none of their SD values was higher than 1 .

\section{Reference gene validation in hREC}

Endogenous gene expression in 12 hREC samples, derived from 3 individual donors (3 unstimulated and 9 stimulated with poly(I:C) for $1 \mathrm{~h}, 6 \mathrm{~h}$ or $24 \mathrm{~h})$ were analysed with each of the 3 mathematical algorithms. Using GeNorm analysis, successive elimination of the least stable genes based on the $M$ values led to the identification of TBP and PGK1 as the most stable pair of reference genes, and $18 \mathrm{~S}$ was considered as the least stable one in all groups (Figure 3A). These 2 genes with the most stable expression were optimal for reliable normalisation in this study, with a pair wise variation lower than 0.15 (Figure 3B). Therefore, the use of the two most stable genes (TBP and PGK1) is sufficient for an accurate normalization.

Analysis of the gene expression of candidate references with NormFinder in hREC found PGK1 as the gene with the lowest stability value (Figure $3 \mathrm{C}$ ), which was similar to results identified by GeNorm.

Table 1 Candidate reference genes for qRT-PCR

\begin{tabular}{lll}
\hline Abbreviation & Gene name & Function \\
\hline I8S & 18S Ribosomal RNA & Ribosomal subunit \\
\hline ACTB & B-actin & Cytoskeletal structural protein \\
\hline B2M & $\beta$-2-microglobulin & $\beta$-chain of major histocompatibility complex class I molecules \\
\hline GAPDH & Glyceraldehyde-3- phosphate dehydrogenase & Oxidoreductase in glycolysis and gluconeogenesis \\
\hline GUSB & beta-glucuronidase & Degradation of determatan and keratin sulfates \\
\hline HPRT1 & Hypoxanthine phosphoribosyl transferase 1 & Purine synthesis in salvage pathway \\
\hline PGK1 & Phosphoglycerate kinase 1 & Glycolytic enzyme \\
\hline$P P I A$ & Peptidylprolyl isomerase A & Catalyzes the cis-trans isomerisation of praline, accelerates protein folding \\
\hline RPLPO & Ribosomal large P0 & Ribosomal protein, translation \\
\hline TBP & TATA binding protein & RNA polymerase II transcription factor \\
\hline
\end{tabular}



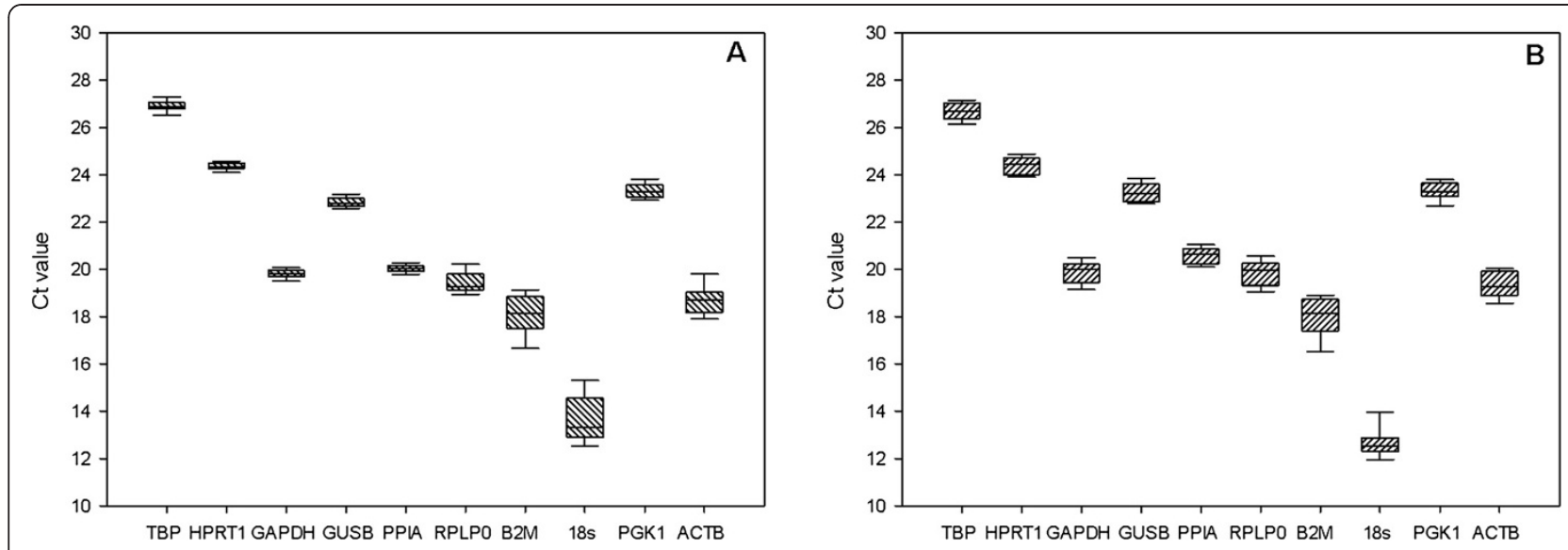

Figure 1 The distribution of gene expression levels of candidate reference genes in hCEC (A) and hREC (B). Values are given as qRT-PCR Ct values. The boxes represent the 25 to 75 percentile ranges with medians (line in the box); the whiskers illustrate the 1 to 99 percentile of the samples.

Ct values were compared in BestKeeper with various combinations of the candidate genes. All of the candidate reference genes showed a SD value lower than 1 (Figure 3D). Further data processing using Repeated Pair-wise Correlation and Regression Analysis assessed HPRT1 as the most stable reference gene, with the lowest standard deviation. $18 \mathrm{~S}$ had the highest variation and the least correlation.
Manipulation of the different EC with poly(I:C) stimulation did not alter the outputs of the 3 different algorithms. This indicates the ability to reproducibly quantify genes with or without stimulation.

We have identified the most stable endogenous control genes in intraocular endothelial cells. It is suggested that future qPCR studies of human intraocular endothelial cells would benefit from adopting the genes identified in
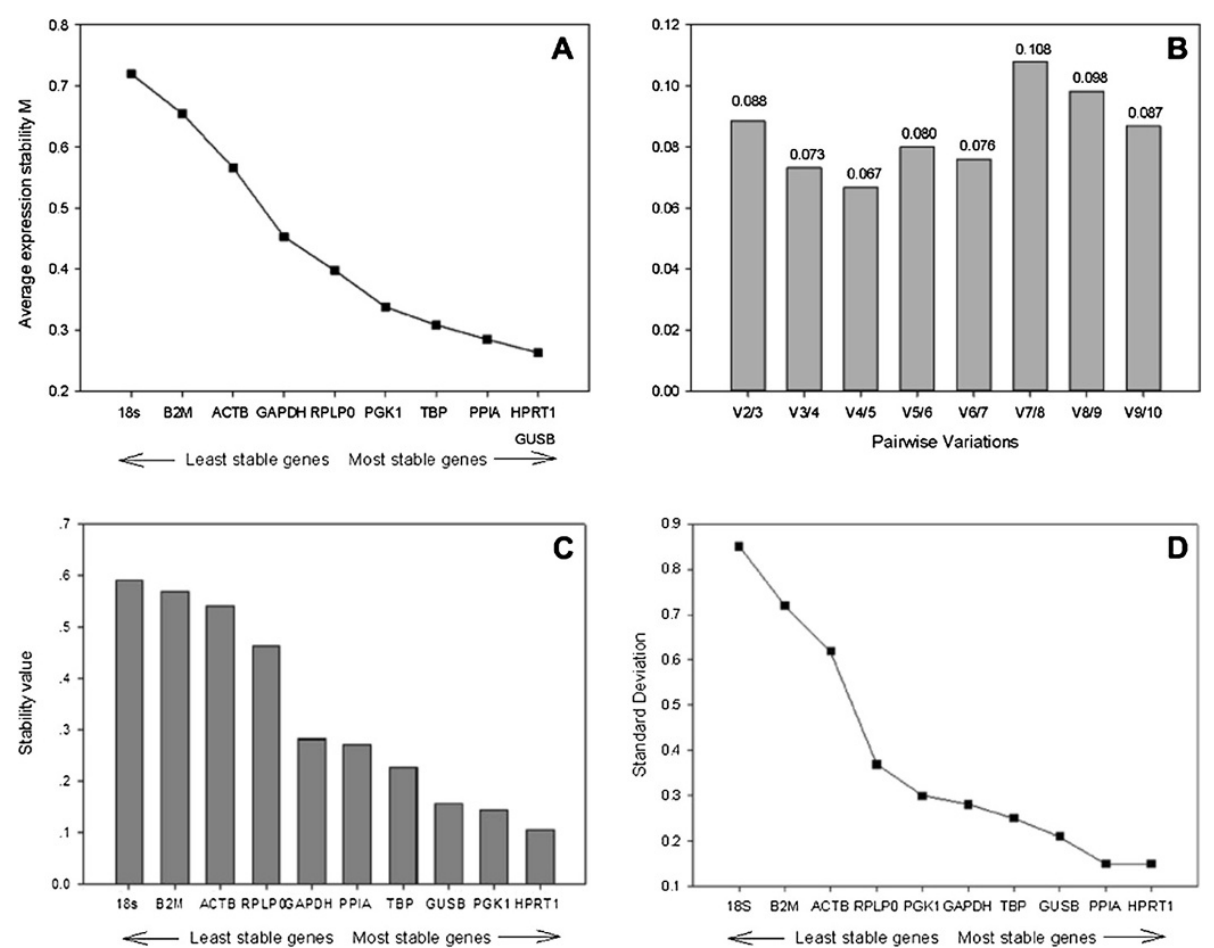

Figure 2 Stability values of reference gene candidates for hCEC qRT-PCR gene expression studies. (A) Average expression stability values of 10 candidate reference genes by stepwise exclusion of least stable genes, using the comparative Ct methods and analysed using the GeNorm algorithm (B) Pair wise variation of candidate gene indicates that 2 reference genes give a low variation so are suitable for normalisation $(<0.15)$, (C) Ct values were transformed into relative quantities using the comparative Ct methods and analysed using the NormFinder algorithm (D) Standard deviation values calculated using BestKeeper, values $<1$ indicate a suitable housekeeping gene. 

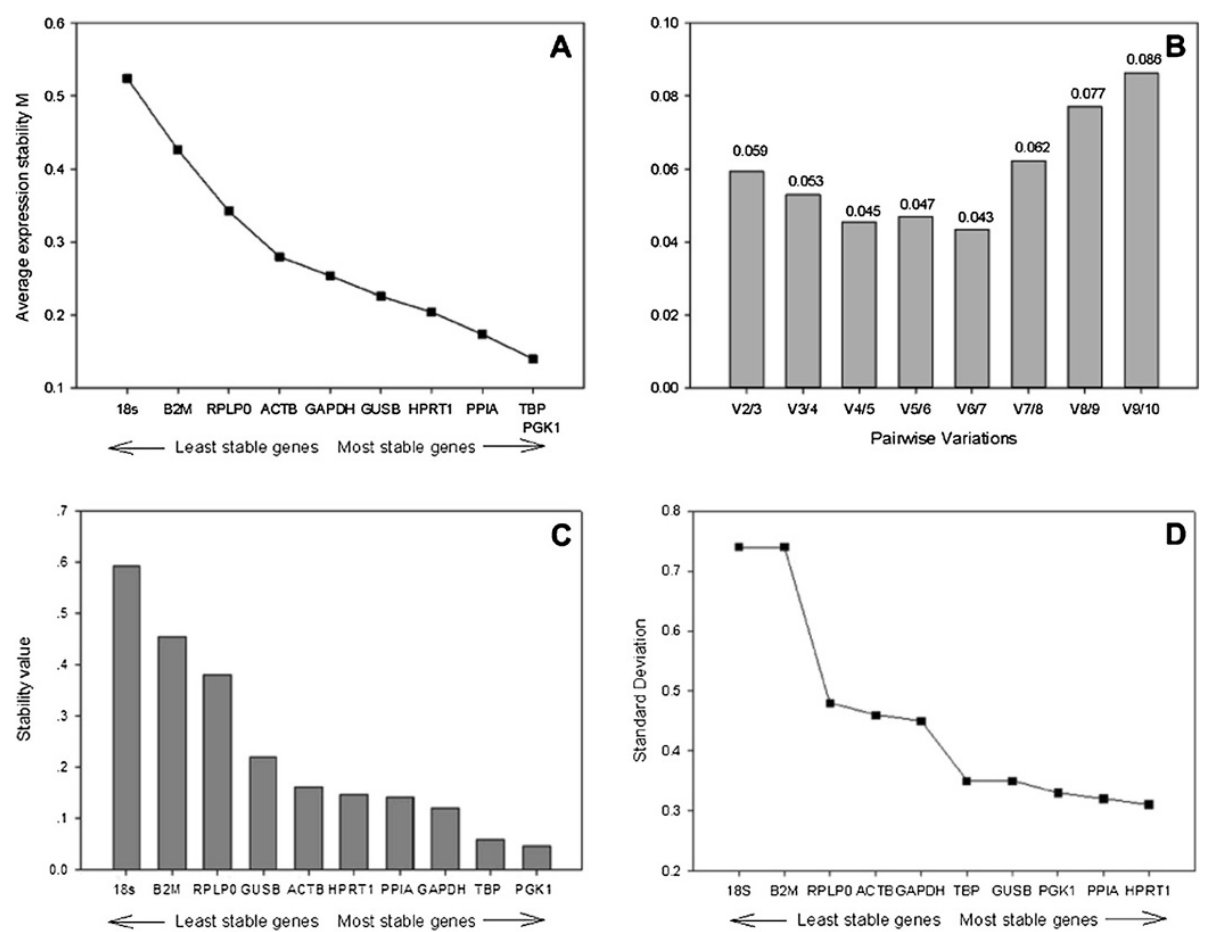

Figure 3 Stability values of reference gene candidates for hCEC qRT-PCR gene expression studies. (A) Average expression stability values of 10 candidate reference genes by stepwise exclusion of least stable genes, using the comparative Ct methods and analysed using the GeNorm algorithm (B) Pair wise variation of candidate gene indicates that 2 reference genes give a low variation so are suitable for normalisation $(<0.15)$, (C) Ct values were transformed into relative quantities using the comparative Ct methods and analysed using the NormFinder algorithm (D) Standard deviation values calculated using BestKeeper, values $<1$ indicate a suitable housekeeping gene.

this study as the most appropriate endogenous control genes. TBP and PGK1 together form the best combination of genes for hREC, and HPRT1 and GUSB for hCEC with GeNorm and Norm Finder, whilst BestKeeper ranked HPRT1 and PPIA are the two most stable reference genes for hCEC (Table 2), and HPRT1 as the most stable reference gene for hREC (Table 3). The least stable gene for hREC and hCEC was $18 S$ with all 3 algorithms.

Table 2 Comparison of ranked endogenous genes in hCEC by all three software

\begin{tabular}{llll}
\hline Gene name & $\begin{array}{l}\text { GeNorm } \\
\text { expression } \\
\text { stability }(\mathbf{M})\end{array}$ & $\begin{array}{l}\text { NormFinder } \\
\text { stability } \\
\text { value }(\boldsymbol{\rho})\end{array}$ & $\begin{array}{l}\text { BestKeeper } \\
\text { coefficient of } \\
\text { correlation }(\boldsymbol{r})\end{array}$ \\
\hline I8S & 0.979 & 0.590 & 0.925 \\
\hline ACTB & 0.927 & 0.541 & 0.668 \\
\hline B2M & 0.954 & 0.568 & 0.658 \\
\hline GAPDH & 0.676 & 0.281 & 0.567 \\
\hline GUSB & 0.555 & 0.156 & 0.479 \\
\hline HPRT1 & 0.531 & 0.105 & 0.579 \\
\hline PGK1 & 0.577 & 0.145 & 0.722 \\
\hline PPIA & 0.608 & 0.270 & 0.307 \\
\hline RPLPO & 0.782 & 0.463 & 0.485 \\
\hline TBP & 0.602 & 0.226 & 0.408 \\
\hline
\end{tabular}

\section{Conclusion}

This study provides the validation of reference genes for RT-qPCR in human microvascular endothelial cells. HPRT1, GUSB and PPIA were recommended as the most stable reference genes for hCEC, HPRT1, TBP and $P G K 1$ for hREC. The results outlined in this article can be applied for future RT-qPCR studies using these cells, and it also indicates a prerequisite for accurate RT-qPCR expression profiling.

\section{Methods}

This research received approval from the local research ethics committee, Nottingham Q1060301.

\section{Stimulation of endothelial cells with poly(l:C)}

Fresh human posterior segments free of any known ocular disease were obtained from Manchester Eye Bank. hCEC and hREC were isolated and cultured from the unpreserved tissue within $48 \mathrm{~h}$ of death using a previously described method [27] .After endothelial cell isolation cells were cultured in endothelial growth medium (EGM2-MV, Lonza) and seeded onto fibronectin (Sigma-Aldrich) coated 35mm culture dishes. The cells were incubated at $37^{\circ} \mathrm{C}$ in a humidified atmosphere of $5 \%(\mathrm{v} / \mathrm{v}) \mathrm{CO}_{2}$ and the medium was changed every 2 days. When the cells were nearly 
Table 3 Comparison of ranked endogenous genes in hREC by all three software

\begin{tabular}{llll}
\hline Gene name & $\begin{array}{l}\text { GeNorm } \\
\text { expression } \\
\text { stability }(\mathbf{M})\end{array}$ & $\begin{array}{l}\text { NormFinder } \\
\text { stability } \\
\text { value }(\boldsymbol{\rho})\end{array}$ & $\begin{array}{l}\text { BestKeeper } \\
\text { coefficient of } \\
\text { correlation }(\boldsymbol{r})\end{array}$ \\
\hline 18S & 0.914 & 0.593 & 0.826 \\
\hline ACTB & 0.457 & 0.161 & 0.885 \\
\hline B2M & 0.743 & 0.453 & 0.779 \\
\hline GAPDH & 0.434 & 0.120 & 0.922 \\
\hline GUSB & 0.462 & 0.219 & 0.689 \\
\hline HPRT1 & 0.412 & 0.146 & 0.830 \\
\hline PGK1 & 0.384 & 0.045 & 0.384 \\
\hline PPIA & 0.412 & 0.142 & 0.839 \\
\hline RPLPO & 0.643 & 0.379 & 0.530 \\
\hline TBP & 0.379 & 0.059 & 0.929 \\
\hline
\end{tabular}

$100 \%$ confluent, hCEC and hREC from each donor were transferred onto fibronectin (Sigma-Aldrich, Gillingham, UK) coated 6-well plates and grown until they reached 70\% confluence. Cells were then incubated with $10 \mu \mathrm{g} / \mathrm{mL}$ poly(I:C) (Invivogen, San Diego, USA) for $1 \mathrm{~h}, 6 \mathrm{~h}$, and 24h, after which lysates were collected with Buffer RLT (Qiagen, Crawley, UK).

\section{RNA extraction and CDNA synthesis}

Total RNA was extracted and purified from the cells using RNeasy Mini RNA kit (Qiagen) according to the manufacturer's protocol. The lysate was homogenized by QIAshredder spin column, and centrifuged for $2 \mathrm{~min}$ at full speed. 1 volume of $70 \%(\mathrm{v} / \mathrm{v})$ ethanol was added to the homogenized lysate and transferred to RNeasy spin column. Buffer RW1 and Buffer RPE was applied to wash the spin column membrane. Finally, total RNA was eluted with $30 \mu \mathrm{L}$ RNase-free water. All the washing and elution steps mentioned above were followed with stepwise centrifugation. RNA was quantified by using a Nanodrop and the quality was determined by agarose gel electrophoresis.

RNA samples were further processed for reverse transcription using the QuantiTect RT kit (Qiagen). $2 \mu \mathrm{g}$ of the purified RNA was incubated with genomic DNA Wipeout Buffer for $2 \mathrm{~min}$ at $42^{\circ} \mathrm{C}$. The reverse-transcription mastermix, containing QuantiTect RT enzyme, QuantiTect RT Buffer and RT Primer Mix, was prepared and added to the template RNA. Samples were incubated at $42^{\circ} \mathrm{C}$ for $15 \mathrm{~min}$, followed by incubating the samples at $95^{\circ} \mathrm{C}$ for $3 \mathrm{~min}$. A $40 \mu \mathrm{L}$ final volume of cDNA was stored at $-20^{\circ} \mathrm{C}$ for real-time PCR.

\section{Real-time PCR (RT-PCR)}

RT PCR was carried out with Roche Lightcycler 480. All samples were diluted 1:5 with nuclease-free water. A single $20 \mu \mathrm{L}$ reaction mixture was prepared to each PCR
Table 4 Details of the Taqman gene assays used for qPCR (primer sequences are proprietary)

\begin{tabular}{lllll}
\hline Gene name & Assay ID & $\begin{array}{l}\text { Accession } \\
\text { number }\end{array}$ & $\begin{array}{l}\text { Probe exon } \\
\text { location }\end{array}$ & $\begin{array}{l}\text { Amplicon } \\
\text { size }\end{array}$ \\
\hline I8S & 4352930E & X03205.1 & NA & 187 \\
\hline ACTB & 4333762T & NM_001101.2 & 1 & 171 \\
\hline B2M & 4333766T & NM_004048.2 & $2-3$ & 75 \\
\hline GAPDH & 4333764T & NM_002046.3 & 3 & 122 \\
\hline GUSB & 4333767T & NM_000181.1 & $11-12$ & 81 \\
\hline HPRT1 & 4333768T & NM_000194.1 & $6-7$ & 100 \\
\hline PGK1 & 4333765T & NM_000291.2 & $4-5$ & 75 \\
\hline PPIA & 4333763T & NM_021130.3 & 5 & 98 \\
\hline RPLPO & 4333761T & NM_053275.3 & 3 & 105 \\
\hline
\end{tabular}

optical tube, with $10 \mu \mathrm{L}$ of $10 \times$ Taqman gene expression master mix (Applied Biosystems, Foster City, CA), $1 \mu \mathrm{L}$ of TaqMan ${ }^{\circledR}$ Gene expression assay (Applied Biosystems; Table 4), $5 \mu \mathrm{L}$ of diluted cDNA and $4 \mu \mathrm{L}$ of nuclease-free water, were performed in optical tubes with optical caps on. Negative controls (non-template control and negative reverse transcriptase control) and positive controls (Universal Human Reference RNA) were also run on the PCR. Amplification conditions were set at $50^{\circ} \mathrm{C}$ for $2 \mathrm{~min}, 95^{\circ} \mathrm{C}$ for $10 \mathrm{~min}, 95^{\circ} \mathrm{C}$ for $15 \mathrm{~s}$ and $60^{\circ} \mathrm{C}$ for $1 \mathrm{~min}$. Each reaction was run in triplicate in a Stratagene MX3005p Quantitative PCR instrument. A total of 12 samples were analysed from 3 pairs of donor eyes in each treatment group at 3 time points.

\section{Data analysis}

The gene expression levels for each of 10 selected potential reference genes were calculated and analysed for comparative stability with the three methods: GeNorm, NormFinder and BestKeeper.

\section{Additional file}

Additional file 1: Results of BestKeeper analyses in untreated and treated hCEC.

\section{Competing interests}

The authors declare that they have no competing interests.

\section{Authors' contributions}

RW carried out the experimental work involved in the study and drafted the manuscript. ES participated in the design of the study, re-drafted and finalised the manuscript. WMA provided the materials, participated in the design of the study and edited the manuscript. All authors read and approved the final manuscript.

Received: 8 October 2012 Accepted: 30 January 2013 Published: 4 February 2013

\section{References}

1. Butte AJ, Dzau VJ, Glueck SB: Further defining housekeeping, or "maintenance," genes Focus on "A compendium of gene expression in normal human tissues". Physiol Genomics 2001, 7:95-96. 
2. Suzuki T, Higgins PJ, Crawford DR: Control selection for RNA quantitation. Biotechniques 2000, 29:332-337.

3. Greer S, Honeywell R, Geletu M, Arulanandam R, Raptis L: Housekeeping genes; expression levels may change with density of cultured cells. J Immunol Methods 2010, 355:76-79.

4. Vandesompele J, De Preter K, Pattyn F, Poppe B, Van Roy N, De Paepe A, Speleman F: Accurate normalization of real-time quantitative RT-PCR data by geometric averaging of multiple internal control genes. Genome Biol 2002, 3:RESEARCH0034.

5. Bustin SA: Absolute quantification of mRNA using real-time reverse transcription polymerase chain reaction assays. J Mol Endocrinol 2000, 25:169-193.

6. Thellin O, Zorzi W, Lakaye B, De Borman B, Coumans B, Hennen G, Grisar T, Igout $A$, Heinen E: Housekeeping genes as internal standards: use and limits. J Biotechnol 1999, 75:291-295.

7. Warrington JA, Nair A, Mahadevappa M, Tsyganskaya M: Comparison of human adult and fetal expression and identification of 535 housekeeping/maintenance genes. Physiol Genomics 2000, 2:143-147.

8. Gebhardt FM, Scott HA, Dodd PR: Housekeepers for accurate transcript expression analysis in Alzheimer's disease autopsy brain tissue. Alzheimers Dement 2010, 6:465-474.

9. Dheda K, Huggett JF, Bustin SA, Johnson MA, Rook G, Zumla A: Validation of housekeeping genes for normalizing RNA expression in real-time PCR. Biotechniques 2004, 37:112-114. 116, 118-119.

10. Akira S, Uematsu S, Takeuchi O: Pathogen recognition and innate immunity. Cell 2006, 124:783-801.

11. Kluwe J, Mencin A, Schwabe RF: Toll-like receptors, wound healing, and carcinogenesis. J Mol Med (Berl) 2009, 87:125-138.

12. Akira S: TLR signaling. Curr Top Microbiol Immunol 2006, 311:1-16.

13. Lee MT, Hooper LC, Kump L, Hayashi K, Nussenblatt R, Hooks JJ, Detrick B: Interferon-beta and adhesion molecules (E-selectin and s-intracellular adhesion molecule-1) are detected in sera from patients with retinal vasculitis and are induced in retinal vascular endothelial cells by Toll-like receptor 3 signalling. Clin Exp Immunol 2007, 147:71-80.

14. Kumar MV, Nagineni CN, Chin MS, Hooks JJ, Detrick B: Innate immunity in the retina: Toll-like receptor (TLR) signaling in human retinal pigment epithelial cells. J Neuroimmunol 2004, 153:7-15.

15. Dasu MR, Devaraj S, Zhao L, Hwang DH, Jialal I: High glucose induces tolllike receptor expression in human monocytes: mechanism of activation. Diabetes 2008, 57:3090-3098.

16. Kleinman ME, Yamada K, Takeda A, Chandrasekaran V, Nozaki M, Baffi JZ, Albuquerque RJ, Yamasaki S, Itaya M, Pan Y, et al: Sequence- and targetindependent angiogenesis suppression by siRNA via TLR3. Nature 2008, 452:591-597.

17. Yang Z, Stratton C, Francis PJ, Kleinman ME, Tan PL, Gibbs D, Tong Z, Chen $\mathrm{H}$, Constantine $\mathrm{R}$, Yang $\mathrm{X}$, et al: Toll-like receptor 3 and geographic atrophy in age-related macular degeneration. N Engl J Med 2008, 359:1456-1463.

18. University of Kentucky Research Foundation: Toll Like Receptor (TLR) Stimulation for Ocular Angiogenesis and Macular Degeneration. 2009, US Patent No. us 0238793.

19. Park DW, Baek K, Lee JG, Park YK, Kim JH, Kim JR, Baek SH: Activation of tolllike receptor 4 modulates vascular endothelial growth factor synthesis through prostacyclin-IP signaling. Biochem Biophys Res Commun 2007, 362:1090-1095.

20. van Beijnum JR, Buurman WA, Griffioen AW: Convergence and amplification of toll-like receptor (TLR) and receptor for advanced glycation end products (RAGE) signaling pathways via high mobility group B1 (HMGB1). Angiogenesis 2008, 11:91-99.

21. Paone A, Galli R, Gabellini C, Lukashev D, Starace D, Gorlach A, De Cesaris P, Ziparo E, Del Bufalo D, Sitkovsky MV, et al: Toll-like receptor 3 regulates angiogenesis and apoptosis in prostate cancer cell lines through hypoxia-inducible factor 1 alpha. Neoplasia 2010, 12:539-549.

22. Pfaffl MW, Tichopad A, Prgomet C, Neuvians TP: Determination of stable housekeeping genes, differentially regulated target genes and sample integrity: BestKeeper-Excel-based tool using pair-wise correlations. Biotechnol Lett 2004, 26:509-515.

23. Andersen $C L$, Jensen $J L$, Orntoft TF: Normalization of real-time quantitative reverse transcription-PCR data: a model-based variance estimation approach to identify genes suited for normalization, applied to bladder and colon cancer data sets. Cancer Res 2004, 64:5245-5250.
24. Foldager CB, Munir S, Ulrik-Vinther M, Soballe K, Bunger C, Lind M: Validation of suitable house keeping genes for hypoxia-cultured human chondrocytes. BMC Mol Biol 2009, 10:94.

25. Robinson TL, Sutherland IA, Sutherland J: Validation of candidate bovine reference genes for use with real-time PCR. Vet Immunol Immunopathol 2007, 115:160-165.

26. de Kok JB, Roelofs RW, Giesendorf BA, Pennings JL, Waas ET, Feuth T, Swinkels DW, Span PN: Normalization of gene expression measurements in tumor tissues: comparison of 13 endogenous control genes. Lab Invest 2005, 85:154-159.

27. Stewart EA, Samaranayake GJ, Browning AC, Hopkinson A, Amoaku WM: Comparison of choroidal and retinal endothelial cells: characteristics and response to VEGF isoforms and anti-VEGF treatments. Exp Eye Res 2011, 93:761-766

doi:10.1186/1756-0500-6-46

Cite this article as: Wei et al.: Suitability of endogenous reference genes for gene expression studies with human intraocular endothelial cells. BMC Research Notes 2013 6:46.

\section{Submit your next manuscript to BioMed Central and take full advantage of:}

- Convenient online submission

- Thorough peer review

- No space constraints or color figure charges

- Immediate publication on acceptance

- Inclusion in PubMed, CAS, Scopus and Google Scholar

- Research which is freely available for redistribution 